\title{
Co-located Nonprofit Centers
}

\section{TENANTS' ATTRACTION AND SATISFACTION}

\author{
Diane Vinokur-Kaplan, ${ }^{1}$ Bowen McBeath ${ }^{2}$
}

${ }^{1}$ The University of Michigan, ${ }^{2}$ Portland State University

\begin{abstract}
Nonprofit centers are organized to house individual nonprofits "under one roof" to enhance their efficiency and effectiveness and to offer shared services to diminish administrative load. This post-occupancy tenant satisfaction survey of three such US centers represents the first empirical analysis of such organizations. We find that nonprofit tenants $(N=118)$ initially co-located due to the leasing price and the new physical environment (free parking and safety). Nearly all nonprofit tenants wished to remain at their nonprofit centers, largely for the same reasons that brought them there. The article then discusses strategies to achieve the high response rates attained in this study. It concludes with some implications for nonprofit centers, communities, and nonprofit staff_ now and in the future, including lower occupancy costs and enhanced quality of nonprofits' workspace.
\end{abstract}

Keywords: nonprofit management, co-location, work environment, management support, shared services, nonprofit efficiency

DURING RECENT YEARS, charitable foundations and government in the United States and Canada have encouraged the adoption of various organizational structures to increase nonprofits' effectiveness and efficiency. For example, some nonprofits are structured as incubators for emerging nonprofits by providing space and guidance (for example, VinokurKaplan and Connor 1999; Centre for Social Innovation 2010; also see Gerl and Associates 2000; and Kinney and Carver 2007). Others have established network structures to enhance service delivery (Chen and Graddy 2010; Eschenfelder 2011). Moreover, other nonprofits have changed their structure through mergers and partnerships. But one other growing organizational structure that has not been researched systematically is co-locations, namely-co-located, multi-tenant nonprofit centers.

These centers all contain separate, independent organizations gathered under one roof. Nonprofit centers are defined as a building or geographic site in which nonprofit

Authors' Note: We gratefully acknowledge financial support from the Aspen Institute Nonprofit Sector Research Fund, the University of Michigan School of Social Work and Office of the Vice-Provost for Research, and one of the nonprofit centers studied in this paper. We would also especially like to thank the executive directors and staff of the three nonprofit centers for their cooperation, and Joyce Carper and Ajay Malhotra for their excellent research assistance.

Correspondence to: Diane Vinokur-Kaplan, The University of Michigan, School of Social Work, 1080 South University Avenue, Ann Arbor, MI 48109-1106. E-mail: dkv@umich.edu 
organizations are co-located in close proximity to one another with some measure of shared space or services (See Vinokur-Kaplan, 2001). Usually, they are co-located within a single building, but they also may be a small campus of coordinated buildings.

Nonprofit centers have been developed to lower occupancy costs for nonprofit tenants, to enhance nonprofit organizations' professional work environments and service delivery, to promote shared services, and to decrease nonprofits' administrative burden through the nonprofit center's administrative office assuming the property management, public safety, and related management tasks. (These centers sometimes also serve as incubators of emerging nonprofits [for example, NEW Center in Ann Arbor, Michigan; Centre for Social Innovation in Toronto, Canada]). Such arrangements also help nonprofits avoid individual laborintensive capital campaigns that distract nonprofit managers from pursuing their missions and may drain the energies of staff and volunteers.

\section{The Rise of Multi-tenant Nonprofit Centers}

More than three hundred such nonprofit centers have been identified throughout the United States and Canada (Nonprofit Centers Network 2014). Indeed, popular interest in such centers is evidenced by the growing organizational membership of the Nonprofit Centers Network, a nonprofit technical assistance organization that promotes and assists in the establishment of healthy, efficient, quality, mission-enhancing workspaces for nonprofit organizations. Reports of communities planning such centers are also noteworthy (for example, see Bradbury et al. 2011).

Some nonprofit centers focus on housing nonprofits concerned with a single nonprofit subsector, such as the arts (for example, the Dairy Center for the Arts in Boulder, Colorado), environmental protection (for example, the Cleveland Environmental Center in Cleveland, Ohio), or human services (for example, the Kikui Center, Honolulu, Hawaii). Other sites house nonprofits representing various subsectors. For example, the NEW (Nonprofit Enterprise at Work) Center in Ann Arbor, Michigan (Vinokur-Kaplan 2001), rents to a mixture of social service, environmental, arts, and other public benefit organizations. Still other centers focus on services for a particular target population (for example, the Women's Center in San Francisco, the Lesbian, Gay, Bisexual and Transgender Community Center in New York City), community, or religion.

These centers are generally developed to lower tenants' costs, to enhance their organizational development, efficiency, and effectiveness, and when relevant, to better coordinate services for clients. By co-locating nonprofits together in one well-designed and well-maintained site, a community can provide nonprofit tenants with improved work environments. These goals are sought through the provision of shared services such as space, reception, and technology and equipment (Alter and Hage 1993; Arsenault 1998; Hutchinson 1999; Kohm 1998; Nonprofit Centers Network 2010). Because the nonprofit landlords of the multi-tenant nonprofit centers focus their attention upon facility maintenance and management, the nonprofit tenants and their directors can be freed from worries regarding malfunctions of physical infrastructure and care of surrounding public space, and they can concentrate more on their mission-based work.

Nonprofit centers are often initiated by existing organizations (Nonprofit Centers Network 2011). They can be subsidized by foundations, thus providing their tenants with 
below-market rents. For example, the McKinley, Longwood, Tides, and Meadows Foundations have established nonprofit centers that offer their tenants below-market rent. These sites have provided nonprofit organizations with modern technological infrastructure, safe, attractive, and well-organized office environments, and access to meeting rooms-a resource for which many of the organizations previously had to pay.

Moreover, the rental costs are further diminished because the nonprofit centers themselves are incorporated as charitable nonprofit organizations (or they are funded through a foundation's program-related investments); therefore the rent they charge to nonprofit tenants does not have to cover the property taxes or related costs typically required by commercial properties. Furthermore, the proximity of the tenant organizations facilitates some types of back office consolidation and joint purchasing (Nonprofit Centers Network 2010; Wallace 2009). Thus, by doubling up and sharing space and facilities under nonprofit auspices, nonprofit tenant organizations can significantly lower their operating costs. The proximity between tenant organizations potentially encourages collaboration or cooperation. Furthermore, these concentrated environments of nonprofits can help raise the profile of the sector in communities (Vinokur-Kaplan 1999), thus potentially attracting more public support.

Despite their common platform of potential benefits for nonprofit tenants, co-located nonprofit centers may differ in the manner in which they were initially organized, their tenant composition (for example, sometimes a few related for-profit organizations become tenants), and the criteria used to admit nonprofit organizations (Alter and Hage 1993; Arsenault 1998; Gerl and Associates 2000; Hutchinson 1999; Kohm 1998). In some cases, nonprofit centers are the result of strategic partnerships among communities, foundations, and public agencies to promote economic development and neighborhood rehabilitation efforts, to redevelop urban centers, or to retain large, nonprofit headquarters in central cities (VinokurKaplan 2000). In other cases, they may represent the creative reuse of unused buildings (for example, empty hospitals, school buildings, or decommissioned military bases) or a means to preserve and sustain historic buildings. Several of these benefits may be incorporated in one site.

To our knowledge, no prior peer-reviewed research has systematically analyzed these nonprofit centers or the nonprofit tenants housed within them. Although the rationale for these centers is clear, no study has examined the perspective of nonprofit tenants regarding what attracts them to the centers, and whether nonprofit tenants are satisfied with their choices and wish to stay there. The current study addresses this knowledge gap by reporting on surveys from three different multi-tenant nonprofit centers. It follows in the tradition of Post-Occupancy Tenant Satisfaction Surveys (Marans and Spreckelmeyer 1981; Zimring 2002) to gauge the satisfaction and retention of tenants once they have moved into a new or renovated building or site. Each nonprofit center studied contains nonprofit tenants from different subsectors. These particular tenants tend to represent the headquarters or administrative offices of each nonprofit, with few, if any direct services being offered on site.

Four research questions guided this research:

1. Who are the tenants? What characterizes nonprofit organizations that have chosen to become tenants at nonprofit centers?

2. Why did they move? What attracted these nonprofits to become tenants at these sites? 
3. Are they satisfied being there? How generally satisfied are nonprofit tenants with their colocation sites? More specifically, how satisfied are they with the site's financial benefits (lower rent), its physical environment, and its professional environment? Is tenants' satisfaction also influenced by their perceived level of support from the facility's management?

4. Retention: Do they wish to remain? If so, for how long?

\section{Description of the Three Multi-tenant Nonprofit Centers Studied}

This study examines these questions through analyses of survey data from 118 nonprofit tenant organizations located at three multi-tenant nonprofit centers in different regions of the United States. All were developed by different foundations. (Centers' names have been changed to preserve their confidentiality.) As seen in the following descriptions, the three sites also differ in their size and focus. In all three cases, a primary founding foundation is located on site.

1. The Downtown Nonprofit Center was established in 1997. It is a renovated multifloor office building in a midsized city, housing mainly diverse nonprofit headquarters that serve communities within the particular city, county, or state. Tenants' rents are half of regular market rates (CEO personal communication 2011), and tenants can stay as long as mutually agreed upon. The center is sponsored by a private foundation.

2. Restoriana consists of a campus of restored historic houses surrounded by a run-down neighborhood within a large US city. The historic district in which it is located was established in 1981. Restoriana primarily houses administrative offices of local- or state-focused nonprofits, especially in education, arts, and human services. The tenants are selected by the sponsoring foundation, which specifically aims to improve these nonprofit organizations' capacities and development. Tenants' rents are free, but organizations can stay a maximum of ten years, except for several tenants who are of particular interest to the foundation that sponsors it.

3. The Greenhouse was established in 1996; it consists of a complex of restored, historic military buildings on a former military base. It is located in a West Coast city, and selects nonprofit organizations dedicated to social justice and environmental protection. Lease costs are below market rate in a particularly expensive real estate market, and leases are renewable. It is sponsored by a large foundation.

\section{Methodology}

Data collection procedures. Data for the current study were collected primarily via self-administered surveys that were to the executive director of each tenant organization during 2000-2001. (It was not possible to survey the other staff due to limited resources.) The executive directors were initially alerted by mail about participating in a study of attitudes and perceptions regarding their nonprofit center. This letter was followed by a questionnaire and a stamped return envelope. In a very few instances, organizations whose executive directors did not have time to complete the full survey were surveyed by e-mail or phone using an abbreviated version of the questionnaire. All respondents received a small compensatory payment for their time. 
Response rates. Following are the number of respondents and the number of tenants in each site (with response rates in parentheses): Downtown Nonprofit Center 49/54 (91 percent); Restoriana 27/27 (100 percent); and the Greenhouse 42/52 (81 percent). These high response rates indicate they well represent the tenants at the three sites.

Instrument. For each site, a fourteen-page questionnaire was developed in consultation with the specific site management team. Each survey included a set of core questions analyzed herein, plus a few additional questions pertaining to specific resources at each site as requested by the executive director. The survey contained primarily closed-ended questions, supplemented by some short, open-ended questions.

Dependent variables. To measure nonprofit tenants' satisfaction about being at the co-location site, two questions were asked: their general level of satisfaction with the center over their stay, using a seven-point Likert scale, ranging from 1 = Very unsatisfied to 7 = Very satisfied; and a five-point version of the same question, "Which statement best represents how your organization feels about being at the specific nonprofit center?," ranging from 1 = "My organization is not at all satisfied being at [name of the specific center]" to 5 = "My organization is very satisfied being at [name of the specific center]." Because responses to these two questions were quite highly correlated $(\mathrm{r}=0.57)$, they were summed together as an index $(\alpha=0.71)$, and the mean was used for analysis. Each tenant was also asked to estimate the number of years that the organization ideally would like to remain on site.

Independent variable. First, each tenant was asked to identify how important each of the following nine listed items was in their decision to locate at the nonprofit center. The nine items were factor analyzed (varimax solution) into three dimensions affecting the motivation to move to a nonprofit center. The first dimension pertained to financial arrangements, using the single item of (1) the site's leasing price. The six-item second dimension concerned the physical environment: (2) the availability of free parking, (3) the physical layout of the offices and facilities, (4) the availability of common meeting rooms, (5) the availability of "break room" facilities, and (6) the site's safety and security $(\alpha=0.74)$. The three-item third dimension pertained to the overall professional environment: (7) the types of organizations already at the site, (8) the opportunity to be in a more professional work environment, and (9) the opportunity for tenants to get help in further developing their organization $(\alpha=0.75)$. Each item was measured via a five-point Likert scale, where $1=$ "This item was not at all important to my organization's decision to relocate to the site" to 5 = "This item was very important. ..." Executive directors also rated how satisfied they were with the nine specific aspects of the respondents' nonprofit center $(1=$ Very dissatisfied to $5=$ Very satisfied $)$.

In addition, tenants rated the general level of support that their organizations had received from various sources. (Support was defined as "information, orientation, and help with your organization's needs as they arise.") This article reports on the degree of support that tenants felt they received from the management team at their site, rated as $1=$ Terrible to $5=$ Excellent.

Open-ended question. To gain further insight into the executive directors' attitudes toward being at the nonprofit center, an open-ended question asked them to write down the greatest benefit and greatest disadvantage of being at the co-location. The executive directors wrote several responses to name the greatest benefits and disadvantages of being at the co-location. These were compiled and coded, and percentages were calculated.

Analysis. One-way analysis-of-variance was employed to measure differences across the three sites in terms of the items that were important to respondents in deciding to move to the 
nonprofit center and their current satisfaction with it. Next, multiple regression estimated the independent influence of the three dimensions (leasing price, physical environment, and professional environment) and management support on tenants' overall satisfaction.

\section{Results}

The following results describe the nonprofit tenants at the three sites and then convey their most important reasons for co-locating, their satisfaction being at their nonprofit center, and the level of their desire to stay at their nonprofit center.

\section{Description of Nonprofit Tenants}

As shown in Table 1, nearly all the tenants had 501(c)3 tax status, except for 13 percent at the Downtown Center and 7 percent at the Greenhouse, and the latter were 501(c)4s. Tenants' length of residence at the three sites varied significantly, given the earlier establishment and the longer leases given by Restoriana (range $=2$ to 216 months, $F=39.3, p<0.001$ ). The majority of tenant organizations were fairly young, established in the 1980s or 1990s: 61 percent at the Downtown Center and Restoriana, and 72 percent at the Greenhouse.

Number of staff and volunteers. Tenant organizations generally had small paid staffs, with the majority at all three sites having fewer than ten staff members; taken as a group, a fifth of all the tenants (20.5 percent) had one staff member or no staff (that is, they were run by volunteers); and 51.4 percent had two to nine paid staff). Other tenants ( 28.1 percent) had 10 to 210 staff (including off-site staff such as troop leaders). Tenants at two of the three sites had considerable numbers of volunteers, with the greatest number at Restoriana (68 percent of the tenants had 100 -plus volunteers, and only 8 percent had none), followed by the Downtown Center (32 percent had 100-plus volunteers, and 23 percent had none), and with the least at the Greenhouse (only 10 percent had a hundred or more volunteers, and 37 percent had none).

Financial status. Tenants' average annual operating budgets ranged from less than $\$ 25,000$ to $\$ 5$ million or more (because some sites housed large anchor agencies). Nearly the majority of all tenants had annual operating budgets of between $\$ 100,000$ and \$999,999: Downtown Center, 58 percent; Restoriana, 71 percent; and the Greenhouse, 44 percent. Those with budgets of $\$ 1$ million or more were most frequently found at the Greenhouse (48 percent), then Restoriana (30 percent), and least at the Downtown Center (22 percent).

\section{Why Did They Move? Importance of Reasons for Co-Locating Initially}

As shown in Table 2, the three nonprofit centers differed regarding the importance of different dimensions influencing tenants to move. Regarding financial arrangements (leasing price), tenants from two of the three sites (Downtown Center and Restoriana) indicated that, on average, the leasing price was a "very important" factor in influencing them to move to a nonprofit center, while tenants from the Greenhouse rated it as "important."

Tenants from all three sites, on average, found the physical environment "important," but less so than the financial arrangements. The items that were rated as "important" ( 4.0 and above) were the free parking and safety at all three sites, plus physical layout at the Downtown Center. 
Table 1. Demographic Characteristics of Nonprofit Tenant Organizations in Three Nonprofit Centers

\begin{tabular}{|c|c|c|c|}
\hline & $\begin{array}{l}\text { Downtown Center } \\
\qquad(N=49)\end{array}$ & $\begin{array}{l}\text { Restoriana } \\
(N=27)\end{array}$ & $\begin{array}{c}\text { Greenhouse } \\
\qquad(N=42)\end{array}$ \\
\hline Organization's Tax-Exempt Status & $(n=48)$ & $(n=27)$ & $(n=30)$ \\
\hline $501(\mathrm{c}) 3$ & $86 \%$ & $100 \%$ & $93 \%$ \\
\hline $501(c) 4$ & $13 \%$ & $0 \%$ & $7 \%$ \\
\hline Total & $99 \%$ & $100 \%$ & $100 \%$ \\
\hline Year Tenant Organization Established & $(n=48)^{\star}$ & $(n=26)$ & $(n=32)$ \\
\hline 1857-1959 & $23 \%$ & $15 \%$ & $13 \%$ \\
\hline 1960-1979 & $17 \%$ & $23 \%$ & $16 \%$ \\
\hline 1980-1989 & $17 \%$ & $46 \%$ & $25 \%$ \\
\hline 1990-1999 & $44 \%$ & $15 \%$ & $47 \%$ \\
\hline Total & $101 \%$ & $99 \%$ & $101 \%$ \\
\hline Number of Staff Full-Time Equivalents, 1998 & $(n=44)$ & $(n=27)$ & $(n=39)$ \\
\hline 0 & $5 \%$ & $0 \%$ & $3 \%$ \\
\hline 1 & $18 \%$ & $0 \%$ & $15 \%$ \\
\hline $2-4$ & $29 \%$ & $33 \%$ & $31 \%$ \\
\hline $5-9$ & $25 \%$ & $33 \%$ & $23 \%$ \\
\hline 10-19 & $14 \%$ & $26 \%$ & $11 \%$ \\
\hline $20+$ & $7 \%$ & $7 \%$ & $18 \%$ \\
\hline Total & $98 \%$ & $99 \%$ & $101 \%$ \\
\hline Number of Volunteers, 1998 & $(n=44)$ & $(n=25)$ & $(n=30)$ \\
\hline 0 & $23 \%$ & $8 \%$ & $37 \%$ \\
\hline $1-9$ & $16 \%$ & $4 \%$ & $40 \%$ \\
\hline $10-49$ & $23 \%$ & $12 \%$ & $7 \%$ \\
\hline 50-99 & $7 \%$ & $8 \%$ & $7 \%$ \\
\hline $100+$ & $32 \%$ & $68 \%$ & $10 \%$ \\
\hline Total & $101 \%$ & $100 \%$ & $101 \%$ \\
\hline Current Annual Operating Budget & $(n=48)$ & $(n=27)$ & $(n=32)$ \\
\hline$<\$ 25,000$ & $4 \%$ & $0 \%$ & $3 \%$ \\
\hline$\$ 25,000-\$ 49,999$ & $2 \%$ & $0 \%$ & $3 \%$ \\
\hline$\$ 50,000-\$ 99,999$ & $13 \%$ & $0 \%$ & $3 \%$ \\
\hline$\$ 100,000-\$ 199,999$ & $6 \%$ & $11 \%$ & $22 \%$ \\
\hline$\$ 200,000-\$ 499,999$ & $27 \%$ & $37 \%$ & $19 \%$ \\
\hline$\$ 500,000-\$ 749,999$ & $15 \%$ & $19 \%$ & $3 \%$ \\
\hline$\$ 750,000-\$ 999,999$ & $10 \%$ & $4 \%$ & $0 \%$ \\
\hline$\$ 1$ million-\$1.9 million & $10 \%$ & $19 \%$ & $22 \%$ \\
\hline$\$ 2$ million-\$4.9 million & $6 \%$ & $7 \%$ & $13 \%$ \\
\hline$\$ 5$ million or more & $6 \%$ & $4 \%$ & $13 \%$ \\
\hline Total & $99 \%$ & $101 \%$ & $101 \%$ \\
\hline
\end{tabular}

Note: *Some percentages do not sum to 100 percent due to rounding 
The professional environment, on average, was only "somewhat important" in influencing the tenants at all three centers to move. Tenants from Restoriana rated the value of being in a more professional work environment and obtaining assistance to further develop their organizations significantly more highly than did those from the other two sites. This result is possibly because tenants at this site were selected so that the sponsoring foundation could help them develop.

\section{Are Tenants Satisfied with Their Nonprofit Centers?}

The tenants vary in their levels of specific satisfaction with the three sites. When the satisfaction with all nine specific items measuring financial arrangements, physical environment and professional environment is averaged, one of the sites reports high satisfaction (Restoriana 4.7/5, a second reports satisfaction (Downtown Center 4.3/5) and a third reports neutrality (Greenhouse 3.6/5).

At two sites, the Downtown Nonprofit Center and Restoriana, the tenants were very satisfied with the financial arrangements (leasing price), and significantly more satisfied on average than tenants at the Greenhouse (see Table 3). Note that the Greenhouse had recently increased tenants' rent (even though they remained below market rates), which might have influenced these findings.

In terms of physical environment items, on average, tenants were satisfied with Restoriana $($ Mean $=4.5)$ and the Downtown Center $($ Mean=4.2) and neutral with the Greenhouse (Mean $=3.7)$. Specifically, the tenants at all three nonprofit center sites were very satisfied with the free parking available. Tenants were also generally satisfied with the safety and

\begin{tabular}{|c|c|c|c|c|c|}
\hline & $\begin{array}{c}\text { Downtown } \\
\text { Center }\end{array}$ & Restoriana & Greenhouse & F-test & Significance \\
\hline \multicolumn{6}{|l|}{ Financial Arrangements } \\
\hline Leasing price & 4.7 & 4.8 & 3.8 & 13.6 & $\star \star \star ~$ \\
\hline \multicolumn{6}{|l|}{ Physical Environment } \\
\hline Physical layout & 4.1 & 3.6 & 3.9 & 3.02 & * \\
\hline Meeting rooms & 3.6 & 3.7 & 3.0 & 3.14 & * \\
\hline Break room facilities & 2.6 & 3.6 & 2.8 & 6.88 & $\star \star$ \\
\hline Free parking & 4.8 & 4.3 & 4.0 & 7.00 & $* * *$ \\
\hline Safety & 4.6 & 4.7 & 4.2 & 2.35 & ns \\
\hline Average & 3.9 & 4.0 & 3.6 & & \\
\hline \multicolumn{6}{|l|}{ Professional Environment } \\
\hline Type of organizations at site & 3.6 & 3.4 & 3.7 & 0.72 & ns \\
\hline More professional environment & 3.6 & 4.1 & 3.0 & 7.20 & 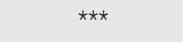 \\
\hline Further develop organization & 3.1 & 4.3 & 2.9 & 10.6 & 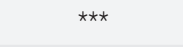 \\
\hline Average & 3.4 & 3.9 & 3.2 & & \\
\hline
\end{tabular}




\begin{tabular}{|c|c|c|c|c|c|}
\hline & $\begin{array}{c}\text { Downtown } \\
\text { Center }\end{array}$ & Restoriana & Greenhouse & F-test & Significance \\
\hline \multicolumn{6}{|l|}{ Financial Arrangements } \\
\hline Leasing price & 4.5 & 5.0 & 3.3 & 35.36 & $\star \star \star \star ~$ \\
\hline \multicolumn{6}{|l|}{ Physical Environment } \\
\hline Physical layout & 4.1 & 4.5 & 3.5 & 10.92 & 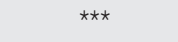 \\
\hline Meeting rooms & 4.1 & 4.1 & 3.0 & 16.45 & $\star \star \star *$ \\
\hline Break room facilities & 3.6 & 4.1 & 3.0 & 10.25 & $\star \star \star \star$ \\
\hline Free parking & 4.8 & 4.9 & 4.7 & 1.14 & ns \\
\hline Safety and security & 4.3 & 4.9 & 4.5 & 5.65 & $\star \star$ \\
\hline Average & 4.2 & 4.5 & 3.7 & & \\
\hline \multicolumn{6}{|l|}{ Professional Environment } \\
\hline Type of organizations at site & 4.3 & 4.3 & 4.1 & 1.18 & ns \\
\hline More professional environment & 4.0 & 4.6 & 3.7 & 7.83 & $\star \star \star *$ \\
\hline Further develop organization & 3.6 & 4.5 & 3.3 & 16.68 & $\star \star \star *$ \\
\hline Average & 4.0 & 4.5 & 3.7 & & \\
\hline Overall average of nine items: & 4.3 & 4.7 & 3.6 & & \\
\hline
\end{tabular}

Note: Scale: 1 = Very dissatisfied, $2=$ Dissatisfied $3=$ Neutral, $4=$ Satisfied, and $5=$ Very satisfied. ${ }^{*} p<.05 ;{ }^{* *} p<.01 ;{ }^{* \star *} p<.001$.

security, with Restoriana tenants the most satisfied, perhaps because their site was patrolled by foundation-sponsored security. The tenants at the Downtown Center and Restoriana were satisfied with the physical layout and meeting rooms at their centers, while those at the Greenhouse were neutral. The tenants at Restoriana were satisfied with the break rooms, whereas tenants at the Downtown Center and the Greenhouse were neutral when compared to the other site.

In terms of professional environment, tenants at all three sites were satisfied with the types of organizations at their sites. Tenants at Restoriana were significantly more satisfied than tenants from the Downtown Nonprofit Center or the Greenhouse with the more professional environment and with opportunities for further developing their organization. Again, this finding may have been influenced by Restoriana's ongoing program of foundation support for tenants' capacity building.

Tenants' overall satisfaction and greatest benefits and disadvantages. When asked their overall satisfaction of being at their nonprofit centers, the tenants on average were quite satisfied, with tenants from Restoriana more satisfied than those from the other two sites (Restoriana Mean $=5.94 / 6$, Downtown Center Mean $=5.30 / 6, t$-test $=-2.47, p<.02$ ) and Greenhouse Mean $=5.16 / 6, t$-test $=4.54, p<.001)$.

In response to the open-ended question regarding the greatest benefit they found in being at their co-location, 43 percent of the responses at both Restoriana and the Greenhouse and 32 percent at the Downtown Center frequently mentioned "the building's location and 
Table 4. Greatest Benefits and Disadvantages of Being at Co-Location

\begin{tabular}{|c|c|c|c|c|c|c|}
\hline & $\begin{array}{c}\text { Greatest } \\
\text { Benefit }\end{array}$ & $\begin{array}{l}\text { Greatest } \\
\text { Benefit }\end{array}$ & $\begin{array}{c}\text { Greatest } \\
\text { Benefit }\end{array}$ & $\begin{array}{c}\text { Greatest } \\
\text { Disadvan- } \\
\text { tage }\end{array}$ & $\begin{array}{c}\text { Greatest } \\
\text { Disadvan- } \\
\text { tage }\end{array}$ & $\begin{array}{c}\text { Greatest } \\
\text { Disadvan- } \\
\text { tage }\end{array}$ \\
\hline & $\begin{array}{c}\text { Downtown } \\
\text { Center }\end{array}$ & Restoriana & $\begin{array}{l}\text { Green- } \\
\text { house }\end{array}$ & $\begin{array}{c}\text { Downtown } \\
\text { Center }\end{array}$ & Restoriana & $\begin{array}{l}\text { Green- } \\
\text { house }\end{array}$ \\
\hline $\begin{array}{l}\text { Respondents of } \\
\text { total }\end{array}$ & $\begin{array}{c}n=46 \text { of } 49, \\
\text { comments }= \\
71\end{array}$ & $\begin{array}{c}n=27 \text { of } 27 \\
\text { comments }= \\
47\end{array}$ & $\begin{array}{c}n=33 \text { of } 52 \\
\text { comments }= \\
54\end{array}$ & $\begin{array}{c}n=42 \text { of } 49 \\
\text { comments }= \\
43\end{array}$ & $\begin{array}{c}n=25 \text { of } 27 \\
\text { comments }= \\
25\end{array}$ & $\begin{array}{c}n=29 \text { of } 52 \\
\text { comments }= \\
46\end{array}$ \\
\hline $\begin{array}{l}\text { Building's location } \\
\text { and ambience }\end{array}$ & $32 \%$ & $43 \%$ & $43 \%$ & $23 \%$ & $12 \%$ & $48 \%$ \\
\hline Social networking & $30 \%$ & $11 \%$ & $31 \%$ & $0 \%$ & $0 \%$ & $0 \%$ \\
\hline $\begin{array}{l}\text { Building services } \\
\text { (e.g., parking, } \\
\text { security) }\end{array}$ & $18 \%$ & $17 \%$ & $17 \%$ & $5 \%$ & $0 \%$ & $33 \%$ \\
\hline $\begin{array}{l}\text { Affordable rent, } \\
\text { cost savings }\end{array}$ & $20 \%$ & $30 \%$ & $6 \%$ & $0 \%$ & $0 \%$ & $0 \%$ \\
\hline $\begin{array}{l}\text { Physical (internal) } \\
\text { space }\end{array}$ & $0 \%$ & $0 \%$ & $0 \%$ & $21 \%$ & $15 \%$ & $9 \%$ \\
\hline None & $0 \%$ & $0 \%$ & $4 \%$ & $40 \%$ & $42 \%$ & $4 \%$ \\
\hline Other & & & & $12 \%$ & $31 \%$ & $6 \%$ \\
\hline TOTAL & $100 \%$ & $101 \%$ & $100 \%$ & $100 \%$ & $100 \%$ & $100 \%$ \\
\hline
\end{tabular}

Note: Some percentages do not sum to 100 percent due to rounding.

Table 5. Standardized Betaweights and Adjusted Multiple Regressions of Tenants at Three Nonprofit Centers and Four Dimensions Influencing Their Satisfaction with Being Located There

\begin{tabular}{lccc}
\hline & Downtown Center & Restoriana & Greenhouse \\
\hline Financial arrangements & -.23 & $.63^{\star \star \star}$ & $.59^{\star \star}$ \\
Physical environment & $.48^{\star \star}$ & -.11 & -.07 \\
Professional environment & -.15 & .13 & -.03 \\
Management support & $.35^{\star \star}$ & .18 & .28 \\
$R$ multiple regression & .58 & .74 & .63 \\
$R^{2}$ adjusted & $.28^{\star \star \star}$ & $.47^{\star \star \star}$ & $.29^{\star}$ \\
\hline
\end{tabular}

${ }^{*} p<.05 ;{ }^{* \star} p<.01 ;{ }^{* \star *} p<.001$.

ambiance" as the greatest benefit. (See Table 4.) Respondents at the Downtown Center and Greenhouse next frequently mentioned "social networking" opportunities (30 and 31 percent respectively) as the greatest benefit, but not those at Restoriana (11 percent) where many tenants are located in separate buildings. Respondents at Restoriana did frequently mention "affordable rent, cost-savings," (30 percent) as the greatest benefit, probably referring to the free rent and other shared services found there, followed by the Downtown Center (20 percent) and the Greenhouse (6 percent).

In response to the open-ended question regarding the greatest disadvantage of being at their co-location, 42 percent of the responses at Restoriana and 40 percent at the Downtown 
Center said there was none (compared to 4 percent at the Greenhouse). The most frequently mentioned disadvantage indeed was at the Greenhouse, regarding the building's location and ambiance (48 percent), compared to the lower percentages at the Downtown Center's (23 percent) and Restoriana (12 percent); this may be because the buildings at the Greenhouse are isolated and have limited access to public transportation.

Multiple regression. To further probe the determinants of tenants' overall satisfaction with being on site, the three factors-financial arrangements, physical environment, and professional environment-plus the rating on perceived management support, were regressed on tenant organizations' overall satisfaction of being at the nonprofit center. (See Table 5.)

The three sites varied somewhat in the dimensions significantly correlated with overall satisfaction. For tenants at Restoriana and the Greenhouse, the financial arrangements (free or belowmarket rent) were the only statistically significant covariates of tenants' overall satisfaction. At the Downtown Nonprofit Center, tenants' satisfaction with the physical environment and management support were positively and significantly correlated with overall satisfaction. The adjusted $R$-squares for overall satisfaction were Downtown Center, $0.28(p<.001)$; Restoriana, $0.47(p<.001)$; and the Greenhouse, $0.29(p<.05)$.

\section{Do Tenants Wish to Remain at Their Nonprofit Centers?}

When asked how long they wished to stay at their sites (irrespective of their leasing arrangements), tenants across the three sites overwhelmingly wanted to remain. Those planning to leave included only 2 percent of respondents from the Downtown Nonprofit Center, 11 percent of Restoriana respondents, and 6 percent from the Greenhouse. Considering the tenants at the three sites as a group, 70 percent stated they would want to stay indefinitely, and 13 percent wanted to stay from seven to twenty years; in contrast, 11 percent planned to stay five years or fewer, and only 6 percent were planning to move immediately.

\section{Discussion}

This first empirical study of multi-tenant nonprofit centers has provided a description and analysis of nonprofit tenants' perceptions of their reasons for locating and remaining at their respective nonprofit centers. In brief, we find, according to the executive directors of the nonprofit tenant organizations, there is high overall satisfaction with being at their co-location. The below-market rent initially most attracts them to the site, followed by selected aspects of the physical environment. Once there, they also report considerable satisfaction with the financial arrangements (leasing price), along with aspects of the physical environment. They also show considerable satisfaction with aspects of the professional environment in which they are now situated.

We used several procedures to help guarantee the successful administration of this survey. First, we gained the cooperation of the nonprofit landlords of the sites and the listings of their tenants by interacting directly and positively with them. They were allowed to preview a draft of the questionnaire and to add a few questions of their own interest. We also supplied them with their results within a reasonable time, giving them information to which they would not otherwise have access.

Second, we believe our high response rate from the executive directors of the tenant organizations was helped by the respondents receiving some small compensation for their time. 
Thus, those wishing to pursue such research will need some resources beyond the usual ones to accomplish such a survey successfully.

Third, the fact that we represented a distant university with no vested interest in the results and promised confidentiality probably raised the response rate. Fourth, the manageable length of the questionnaire (taking about fifteen minutes) also helped, because it did not impose an undue burden on the executive directors' time. Fifth, we followed up with the respondents to encourage them to submit their questionnaires, and that again may have raised their participation rate. Sixth, we promised (and delivered) summaries of the survey results to each respondent who wanted them.

Finally, we recommend that questions about overall level of satisfaction should be asked twice, as we did, once at the beginning of the questionnaire and again, in another format, at the end, to raise the reliability of measuring this attitude.

We also learned three ways this study could have been improved. First, and most important, this study could ask specifically about whether being at the center influences each tenant's fulfillment of its mission. Mission fulfillment is the goal of every nonprofit organization, so it is important to know whether tenancy at a nonprofit center helps them become more effective.

Second, had resources been available, this study of multi-tenant nonprofit centers could have included attitudes and satisfaction of staff and volunteers at each site. Their inclusion would have provided a fuller view of the impact of this work environment on mission-based outcomes and organizational culture (confer Schein 2010). Indeed, the executive directors who responded to this survey also could have been asked how the move had influenced the culture of their organizations. It would then be interesting to compare any differences in executives' and staff's opinions to know how to better design such nonprofit centers.

Third, we noted that fewer than 20 percent of the respondents wanted to leave in five years or fewer or to move immediately. Further research should probe the reasons for this minority wanting to depart. Is it dissatisfaction with the site's leasing arrangements and physical or professional environment? Or, in contrast, do they think that they will grow and thus expand their staff beyond the space available at a nonprofit center's site?

In hindsight, we also have the following concerns about the study. First, it is limited to only three sites that were intentionally developed by charitable foundations, while there are more than three hundred identified sites in the United States and Canada that well may have had other origins and experiences. Second, because some time had passed since some of the tenants moved in (in at least one case, eighteen years), it is possible that the responding nonprofit executive directors may not have accurately recalled the relative importance of various items in leading their organizations to move and co-locate. Third, data are limited to those nonprofits that were accepted and actually moved to a nonprofit center. We would be curious to know if and why some accepted tenants did not move to the site.

\section{Implications}

This study has demonstrated that it is possible to conduct a post-occupancy tenant satisfaction survey of nonprofit organizations at different, co-located nonprofit centers. It has underlined the importance of beneficial leasing arrangements, the appropriate physical 
environment: (for example, free parking, and safety and security), and support from site management not only when inducing nonprofit organizations to move to nonprofit centers, but also when satisfying tenants once they are there.

We conclude with some practical suggestions that nonprofit managers, private foundations, and communities might consider in better promoting co-locations. To begin with, there should be raised awareness among foundations and other community funders that nonprofits' rent and related occupancy costs can be lowered through development of nonprofit centers because the nonprofit landlords are exempt from property taxes. Because occupancy is often the second-largest line item in nonprofits' budgets after salaries and wages, these centers can be seen as long-range investments in making the sector more efficient, especially for small, voluntary nonprofits; those same funds once paid for rent now instead can be designated to essential programs and mission. Indeed, nonprofit landlords keep these dollars within the nonprofit sector, which can be "leveraged for the long term to increase capacity in the sector" (Brotsky 2004, 2).

Also, there should be raised public awareness that organizational space matters to nonprofits and their workforces and should not be an afterthought. Unfortunately, little attention has been given to the built environment in which nonprofit organizations, their staffs, and their volunteers function. This knowledge gap has occurred despite other organizational studies that document both the positive effects that constructive work environments can have on worker productivity, health, and job satisfaction (Brill et al. 2001; Kaplan 1992; McCoy and Evans 2004), and the negative effects that the stress and distraction found in noisy, uncomfortable, or unsafe workplaces can have on communication, productivity, and job dissatisfaction (Herzberg 1987; Kniffen 2005; McCoy and Evans 2004; Tierney 2012). For example, pleasant work environments may positively influence workers' and volunteers' productivity by abating such stressors as noise, pollution, and poor lighting (McCoy and Evans 2004), thereby both enhancing their effectiveness and efficiency, and also enhancing their desire to remain on site.

These relationships among physical working conditions, nonprofits' organizational development, and their staffs' productivity and satisfaction are growing increasingly important; the nonprofit sector will increasingly need to attract and retain qualified executives, staff members, board members, and volunteers to its workforce because of the increasing number of nonprofits (Roeger, Blackwood, and Pettijohn 2012) and the retirement of nonprofit professionals and volunteers due to generational succession (Tierney 2006). Nonprofits will be in competition with business and government for coveted employees, and an organization's physical facilities and on-site amenities may well be useful for recruiting and retaining a capable workforce.

The organization's physical environment may also symbolize the culture and quality of the organization to workers, volunteers, board members, and other internal stakeholders; thus, it may also increase their motivation and induce greater participation from them. Buildings populated with nonprofit organizations can also become local landmarks for the community, thereby strengthening the salience and importance of the nonprofit sector in the community (Vinokur-Kaplan 1999).

In general, managers of nonprofit organizations deal with the human resource, public image, and financial issues related to their organizations (Grønbjerg and Nagle 1994; Salamon and Gellers 2006); however, they may not be specifically educated to deal with the demanding technical issues around real estate development and facilities management (Hurley 2000). 
Thus, it is important that nonprofit centers be led and managed by those familiar with—or trained in-facility management and finance.

Otherwise, nonprofit executives face great difficulties in competently purchasing property, financing renovations, or improving equipment systems in their workplaces. For example, significant percentages of nonprofit directors in the 2006 Listening Post survey stated that it was "fairly or extremely difficult" to raise capital needed for buildings and land from government (63 percent), commercial banks ( 49 percent), foundations ( 49 percent), or individual donors (44 percent), (Salamon and Gellers 2006, Table 1, p. 8). Fortunately, such financial issues can be addressed more effectively by those with relevant real estate expertise to create, manage, and oversee a nonprofit center.

Although it is obvious that small and mid-sized nonprofits face serious financial constraints, their executive directors in this study report that below-market rental rates at nonprofit centers are both an inducement to move to nonprofit centers and a source of satisfaction for them when there. We hope that growing public appreciation of the need to repair and renew public infrastructure will also be applied to nonprofit infrastructure, because it would help communities establish more nonprofit centers to provide public benefits. We also urge that further research be conducted on more of these emerging nonprofit centers to better understand their sustainability.

\section{References}

Alter, C., and J. Hage. 1993. Organizations Working Together. Newbury Park, CA: Sage.

Arsenault, J. 1998. Forging Nonprofit Alliances. San Francisco: Jossey-Bass.

Bradbury, S., K. Edwards, G. Laca, and A. Maher. 2011. "Building co-location: A report for the Marion County Commission on Youth (MCCOY) and the Early Intervention and Prevention (EIP) Initiative." Indianapolis: Collaboration of Local Organizations (CoLO). School of Public and Environmental Affairs, Indiana University-Purdue University-Indianapolis.

Brill, M., and S. Weidemann, and BOSTI Associates. 2001. Disproving Widespread Myths about Workplace Design. Jasper: Kimball International.

Brotsky, C. 2004. "Shared Spaces: Multi-Tenant Centers Are Making Rents More Affordable for Nonprofits." Grantsmanship (Fall). www.tgci.com/magazine/04fallspaces2.asp.

Centre for Social Innovation. (2010). Emergence: The Story of the Centre for Social Innovation. Toronto, Canada (Creative Commons Attribution 2.5). http://www.lulu.com/shop/the-centre-for-social-innovation/ emergence-the-story-of-the-centre-for-social-innovation/paperback/product-11595561.html.

Eschenfeld, B. 2011. "Funder-Initiated Integration: Partnership Challenges and Strategies." Nonprofit Management and Leadership 21(3): 273-88.

Gerl, E., and Associates. 2000. Incubating the Arts: Establishing a Program to Help Artists and Arts Organizations Become Viable Businesses. Athens, OH: National Business Incubator Association Publications.

Grønbjerg, K. A., and A. E. Nagle. 1994. "Structure and Adequacy of Human Service Facilities: Challenges for Nonprofit Managers.” Nonprofit Management and Leadership 5 (2): 117-40.

Herzberg, F. 1987. "One More Time: How Do You Motivate Employees?” Harvard Business Review (September-October): 1-16. Reprint No. 87507.

Hurley, M. 2000. “Securing a Safe Haven: Facilities Strategies for San Francisco's Nonprofits.” Julie Brandt and Pam David, Mayor's Office of San Francisco, for an MPP [Master of Public Policy] internship in Housing, Urban Development and Transportation, Kennedy School of Government, Harvard University.

Hutchinson, K. 1999. Getting It Together: Collaboration Models for Community Groups. Vancouver, British Columbia, Canada: British Columbia Council for Families Community Agency Partnership Project. 
Independent Sector. n.d. “The Sector's Economic Impact.” www.independentsector.org/economic_role.

Kaplan, R. 1992. "The Psychological Benefits of Nearby Nature." In The Role of Horticulture in Human Well-Being and Social Development: A National Symposium, edited by D. Relf, 125-33. Portland, OR: Timber Press.

Kinney, N. T., and M. L. Carver. 2007. Urban Congregations as Incubators of Service Organizations. Nonprofit Management and Leadership 2 (3): 193-214.

Kniffen, A. 2005. "Workplaces That Work: Increasing Employee Retention and Satisfaction. HR.COM. July1. www.hr.com/en/communities/labor_relations/workplaces-that-work-increasing-employee-retention_ ead22ybz.html.

Kohm, A. 1998. "Cooperating to Survive and Thrive: Innovative Enterprises among Nonprofit Organizations." Nonprofit World 16:36-44.

Marans, R. W., and K. F. Spreckelmeyer. 1981. Evaluating Built Environments: A Behavioral Approach. Ann Arbor: Survey Research Center, Institute for Social Research, University of Michigan.

McCoy, J. M., and G. W. Evans. 2004. "Physical Work Environment." In Handbook of Work Stress, edited by J. Barling, E. K. Kelloway, and M. R. Frone. Thousand Oaks, CA: Sage.

Nonprofit Centers Network. 2010. Shared Services: A Guide to Creating Collaborative Solutions for Nonprofits. San Francisco: Tides (Foundation).

- 2011. Measuring Collaborations: The Benefits and Impacts of Nonprofit Centers. San Francisco: Nonprofit Centers and Tides (Foundation).

— 2014 "Center List of Alphabetized Directory." Accessed July 13. www.nonprofitcenters.org/centers/ view-alphabetized-directory/.

Roeger, K. L., A. S. Blackwood, and S. L. Pettijohn. 2012. Nonprofit Almanac 2012. Washington DC: Urban Institute Press.

Salamon, L. M., and S. L. Geller. 2006. Investment Capital: The New Challenge for American Nonprofits. Listening Post Project Communiqué no. 5. Baltimore: Johns Hopkins University Center for Civil Society Studies at the Institute for Policy Studies.

Schein, Edgar H. 2010. Organizational Culture and Leadership. San Francisco: Jossey-Bass.

Tierney, J. 2012. "From Cubicles, Cry for Quiet Pierces Office Buzz." New York Times, May 20, pp. 1, 18.

Tierney, T. J. 2006. The Nonprofit Leadership Deficit. Boston: Bridgespan Group.

Vinokur-Kaplan, D. 1999. "Nonprofit Centers Arising: Symbolic Expression of Organizational and Community Nonprofit Values and Capacities through Architecture." Paper presented at the Annual Meeting of the Association for Research on Nonprofit Organizations and Voluntary Action, Crystal City, VA, November.

- 2001. "Under One Roof: Designing and Financing Nonprofit Co-Locations." Presentation at the Second Annual Conference of the Alliance for Nonprofit Management, Cleveland, March.

Vinokur-Kaplan, D., and J. A. Connor. 1999. "Nonprofit Incubators: Comparative Models for Nurturing New Third Sector Organizations.” Presentation, Biennial Conference of the International Society for Third Sector Research, Geneva, Switzerland, July.

Wallace, N. 2009. "Joining Forces in the Back Office." Chronicle of Philanthropy. http://philanthropy.com/ premium/articles/v21/i11/11003301.

Zimring, C. 2002. "Postoccupancy Evaluation: Issues and Implementation." In Handbook of Environmental Psychology, edited by R. E. Bechtel and A. Churchman. New York: Wiley.

DIANE VINOKUR-KAPLAN is associate professor in the School of Social Work at the University of Michigan.

BOWEN MCBEATH is associate professor in the School of Social Work at Portland State University. 